\title{
Reducing referral delays in colorectal cancer diagnosis: is it about how you ask?
}

\author{
Hardeep Singh, ${ }^{1}$ Laura A Petersen, ${ }^{1}$ Kuang Daci, ${ }^{2}$ Clyde Collins, ${ }^{2}$ \\ Myrna Khan, ${ }^{1}$ Hashem B El-Serag ${ }^{3}$
}

${ }^{1}$ Houston VA HSR\&D Center of Excellence, and The Center of Inquiry to Improve Outpatient Safety Through Effective Electronic Communication, both at the Michael E DeBakey Veterans Affairs Medical Center and the Section of Health Services Research, Department of Medicine, Baylor College of Medicine, Houston, Texas, USA ${ }^{2}$ Department of Medicine, Baylor College of Medicine, Houston, Texas, USA

${ }^{3}$ Section of Gastroenterology and Hepatology, Michael E DeBakey Veterans Affairs Medical Center and Houston VA HSR\&D Center of Excellence, Department of Medicine, Baylor College of Medicine, Houston, Texas, USA

\section{Correspondence to}

Dr Hardeep Singh, VA Medical Center (152), 2002 Holcombe Blvd, Houston, TX 77030, USA; hardeeps@bcm.tmc.edu

Accepted 19 December 2009 Published Online First 27 June 2010

\section{ABSTRACT}

Objectives Delays in colorectal cancer (CRC) diagnosis related to colonoscopy referrals are not well studied. The authors tested whether certain details of information transmitted through computerised provider order entry (CPOE)-based referrals affected timeliness of diagnostic colonoscopy for patients with newly diagnosed CRC.

Methods The authors studied a 6-year cohort of all newly diagnosed patients with CRC at a large tertiary care Veterans Affairs hospital and its affiliated multispecialty clinics. Referring providers included primary care clinicians, resident trainees and other specialists. From the colonoscopy referral preceding CRC diagnosis, the authors determined request date, type and frequency of diagnostic clues provided (symptoms, signs, test results), notation of urgency, and documented evidence of verbal contact between referring provider and consultant to expedite referral. The authors compared distributions of proportions of diagnostic clues between patients with a lag of $>60$ and $\leq 60$ day, and examined predictors of lag time.

Results Of 367 electronic referrals identified with a median lag of 57 days, 178 (48.5\%) had a lag of $>60$ days. Referrals associated with longer lag times included those with 'positive faecal occult blood test' (92 days, $p<0.0001$ ), 'haematochesia' (75 days, $p=0.02$ ), 'history of polyps' (221 days, $p=0.0006$ ) and when 'screening' (vs specific symptoms) was given as the reason for diagnostic colonoscopy (203 days $p=0.002$ ). Independent predictors of shorter wait times included three diagnostic clues, notation of urgency and documentation of verbal contact.

Conclusions Attention to certain details of diagnostic information provided to consultants through CPOE-based referrals may help reduce delays in CRC diagnosis.

\section{INTRODUCTION}

Delayed colorectal cancer (CRC) diagnosis is one of the most common reasons for ambulatory diagnostic malpractice claims in the USA. ${ }^{12}$ Contributing factors in delayed CRC diagnosis include patient-related delays in seeking care and scheduling procedures, provider-related delays in ordering tests, and limited endoscopic capacity. ${ }^{3-7}$ We recently described the prevalence and types of missed opportunities for detecting and investigating clues that could have led to an earlier referral for colonoscopy. ${ }^{8}$ When we examined determinants of wait time between referral and diagnosis of CRC in a large tertiary care facility, we found that patients with symptoms related to CRC, abnormal lab tests or abnormal imaging studies had a shorter lag time between referral and diagnosis compared with patients who had a positive screening test. ${ }^{9}$ These data suggest that the nature of referral information provided to the gastroenterologist could influence lag time between referral and colonoscopy performance.

In many integrated electronic medical records (EMRs), practitioners use computerised provider order entry (CPOE) to generate referral requests and relay relevant clinical information to the consultant. Studies of non-CPOE referrals have shown that providers do not consistently provide accurate clinical information on referral requests. ${ }^{10-12}$ Whether the nature and amount of information influence the outcome of the referral is not clear. For instance, the documentation of certain diagnostic clues or flagging referrals as 'urgent' may be associated with shorter lag times for colonoscopy. We sought to determine the association between the quality and quantity of information transmitted in colonoscopy requests using CPOE and the timeliness of colonoscopy performance. We also examined the characteristics of referral requests associated with time lags of greater than 60 days from initial request to colonoscopy performance.

\section{METHODS}

We studied a cohort of all newly diagnosed patients with confirmed primary CRC diagnosed between June 2001 and June 2007 at a tertiary care Veterans Affairs facility. Colonoscopy referrals are entered through a CPOE system, which has been used in the VA setting for close to a decade (figure 1). Most outpatient referrals are initiated by approximately 50 primary care providers who practice at the facility or at one of its five community-based satellite clinics. Other referring providers include resident trainees and specialists. Most inpatient referrals are initiated by residents on medical or surgical floors. Requests are then screened by several gastroenterologists on a rotating basis. At this institution and many others, endoscopic capacity is limited by the number of endoscopy rooms, preparation and recovery space, and availability of gastroenterologists.

We examined referrals that requested a diagnostic colonoscopy or sigmoidoscopy or requested the consultant to address certain diagnostic clues suggestive of CRC. We thus focused our study only on patients for whom the referring physician requested a diagnostic colonoscopy or screening for high-risk individuals. The primary modality of CRC screening in the VA is faecal occult blood test (FOBT), and only a small proportion of 
Figure 1 Order-entry template for colonoscopy referrals.

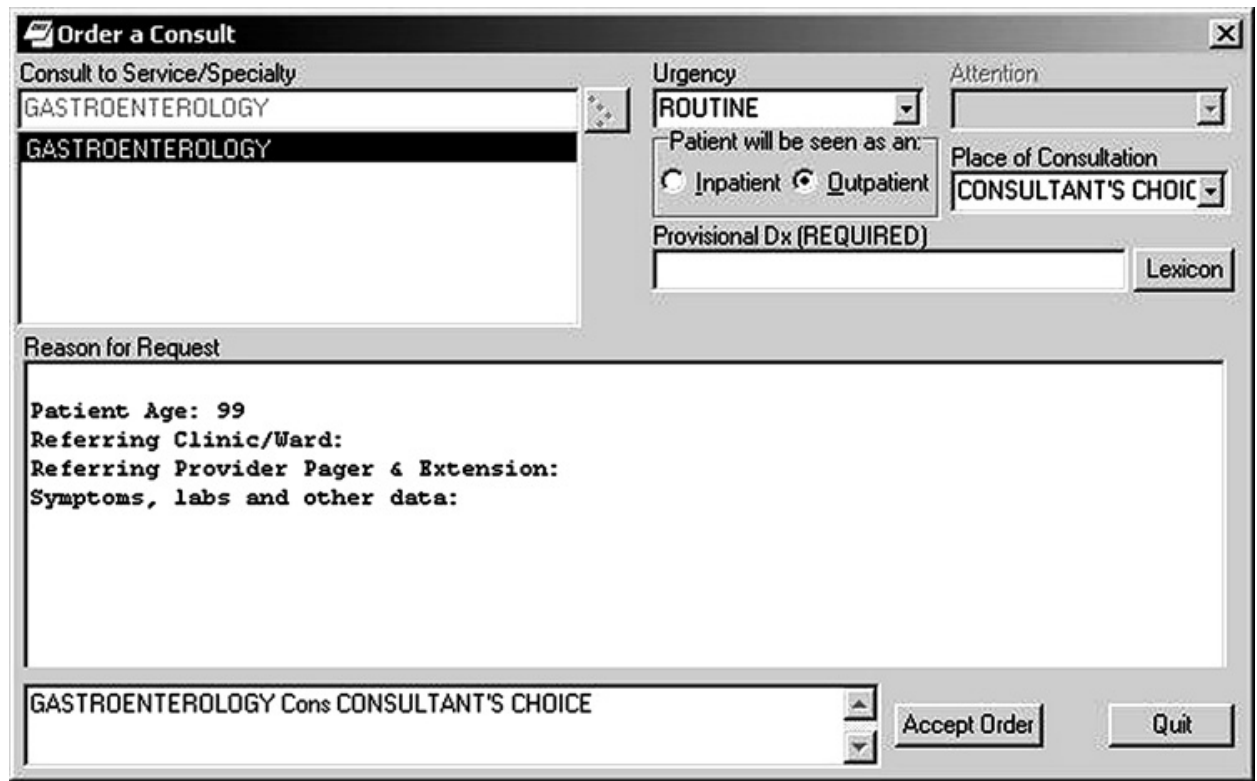

colonoscopies requested are related to screening in average risk individuals. ${ }^{13} 14$

We excluded patients diagnosed (or who received their CRC diagnosis care) outside the institution and those with recurrent CRC. We also excluded CRC diagnosed by colonoscopy requested solely for screening in otherwise asymptomatic patients. Using the integrated EMR, we conducted a detailed review of information contained in the electronic referral request, as well as colonoscopy performance and patient characteristics. Currently the only information templated is patient age, referring clinic/ward, details of referring provider and their contact information, and free-text information about symptoms, labs and other data. For patients with more than one referral, we examined only the first request. The study was approved by the local Institutional Review Board.

\section{Data collection procedures}

Prior to the study, we designed and pilot-tested a data-collection instrument for the variables of interest. The study team supervised and trained reviewers to ensure reliable and consistent data collection. Reviewers documented the following:

1. Referral request information: Date of request; type of information provided in the request (ie, diagnostic clues such as symptoms, signs, test results); referral origin (inpatient or outpatient); notation of urgency ( $<7$ days, $<30$ days, next available, or routine); specialty of the referring provider; and documented evidence of verbal contact between referring provider and consultant to expedite referral. Based on our previous work, ${ }^{8}$ we started with a list of diagnostic clues a priori but further developed it as we gathered new information. To evaluate the quantity of information provided to the consultant, we documented the number of diagnostic clues provided in the referral request.

2. Outcome: We recorded whether an appointment for colonoscopy was generated subsequent to the referral, and if so, the date colonoscopy was performed and any patient nonadherence (no show, cancellation).

\section{Data analysis}

Our primary outcome was the median number of days between first colonoscopy referral and colonoscopy performance. A VA directive recommends a colonoscopy completion time of 60 days after a positive FOBT. ${ }^{15}$ Therefore, we also analysed wait times as a binary variable ( $\leq 60$ days or $>60$ days from referral to colonoscopy). We used several methods to determine the relationship of referral characteristics to lag time. We used $\chi^{2}$ tests for categorical variables, Fisher exact test when the assumptions for $\chi^{2}$ were not met, and non-parametric quantile regression for models with median wait time as the outcome. Quantile regression is used when parametric assumptions cannot be met and is a more robust analogue of least-squares regression under conditions of non-normality and heterogenous variability. ${ }^{16} 17$ Quantile regression models the relation between a set of independent variables and specific percentiles or quantiles of the outcome variable. Because the distribution of wait times was highly skewed, we used a median (a quantile describing the central location of the distribution) regression model to specify the changes in median wait times as a function of the predictor variables.

Predictor variables included the frequency of diagnostic clues (symptoms, signs, test results), referral origin (inpatient or outpatient), marking of urgency ( $<7$ days, $<30$ days, next available or routine), the specialty of the requesting provider (primary care vs subspecialist) and documented evidence of verbal contact between referring provider and consulting services to expedite referral. We also tested patient demographics (age, gender, race) and clinical factors (eg, comorbid medical or psychiatric disorder) as predictors of wait time. Potential predictor variables were examined in an unadjusted model, and those with $p<0.1$ were included in a multivariate model. Only covariates with significant $(p<0.1)$ as well as stable risk estimates were kept in the final model. Data were analysed using SAS software (SAS Institute, version 9.1.3; SAS Institute, Cary, North Carolina).

\section{RESULTS}

Between June 2001 and June 2007, 367 patients with CRC fulfilled selection criteria and had electronic referral requests for colonoscopy/sigmoidoscopy prior to CRC diagnosis. The median wait time between referral and colonoscopy performance was 57 days. Almost half (48.5\%) of patients had wait times $>60$ days. 
Table 1 shows the distribution of median wait times by patient characteristics. Patients with congestive heart failure, coronary artery disease and diabetes had significantly longer median wait times to colonoscopy than patients without these disorders ( $p$ values $\leq 0.02$ ). Patients with depression and posttraumatic stress disorder also had significantly greater wait times ( $p=0.006$ and $p=0.04$, respectively). Demographic variables were not associated with differences in median wait times. Demographic and health characteristics were similar at the beginning and end of the study period, with the exception that hypertension was more prevalent in 2007 (77.8\%) than in 2001 $(54.3 \%) \quad p=0.02$. However, when we collapsed medical and psychiatric conditions across subcategories, we found that the presence of any psychiatric condition was more frequent in 2001 $(\mathrm{p}=0.09)$.

Table 2 shows median wait times for patients with diagnostic clues provided in the referral request and compares the proportions of diagnostic clues between patients with $\leq 60$ and $>60$-day wait times. Referrals with longer wait times contained positive FOBT, rectal bleeding, history of polyps and requests for 'screening' in the presence of other diagnostic clues.

Table 3 shows univariate associations between referral request characteristics and wait time to colonoscopy. Referrals that originated in the inpatient setting were associated with shorter wait times than outpatient referrals. Approximately half of referrals were marked as 'routine'; all others were associated with shorter wait times, particularly those marked as needed in less than 1 week. In approximately $12 \%$ of outpatient referrals, providers documented additional verbal contact with the gastroenterology service, and these requests were also associated with shorter wait times. Referrals followed by one or more episodes of patient non-adherence were associated with the longest median wait time.

Table 4 shows the results from the final multivariable quantile regression model. The following variables were significant independent predictors of shorter wait times: referrals with three clues, inpatient referrals, referrals with urgency marked for $<1$ week or $<30$ days, referrals marked 'next available' and outpatient referrals in which verbal discussion with a consultant was documented. A gradient effect for the number of clues may not be evident due to sample size limitations, as the majority of referrals documented one or two clues. Only 46 referrals had three documented clues, and 10 referrals had four or more clues.

\section{DISCUSSION}

We evaluated referrals for 367 patients diagnosed as having CRC over a 6-year period to determine if the timeliness of diagnostic colonoscopy was associated with the quality and quantity of information transmitted via the CPOE-generated referral request. Our findings suggest that in a system with limited endoscopic capacity, both quality and quantity of information transmitted to the consultant affected the wait time between referral and colonoscopy. Shorter wait times were associated with referral requests that documented three diagnostic clues versus one clue, originated in the inpatient setting, were marked as urgent or next available (vs routine), and documented a verbal discussion with a consultant. Clues such as iron-deficiency anaemia, abnormal CT scan or barium enema, suspected mass on physical examination, abdominal pain and obstruction were

Table 1 Distribution of median wait times between referral and performance of colonoscopy for several patient characteristics; results of univariate analyses

\begin{tabular}{|c|c|c|c|c|c|c|}
\hline & \multirow[b]{2}{*}{ N (\%) } & \multirow[b]{2}{*}{ Median time } & \multicolumn{4}{|c|}{ Quantile regression } \\
\hline & & & Coefficient & SE & T Value & p Value \\
\hline \multicolumn{7}{|l|}{ Age } \\
\hline$<65$ & $143(39.0)$ & 50.0 & Referent & & & \\
\hline $65-74$ & $108(29.4)$ & 63.0 & 13.0000 & 16.3631 & 0.79 & 0.43 \\
\hline$>75$ & $116(31.6)$ & 57.0 & 7.0000 & 16.0384 & 0.44 & 0.66 \\
\hline \multicolumn{7}{|l|}{ Race } \\
\hline White Caucasian & $187(57.0)$ & 57.0 & Referent & & & \\
\hline Black & $112(34.2)$ & 45.0 & -19.3445 & 14.5651 & -1.33 & 0.18 \\
\hline Hispanic, other & $29(8.8)$ & 61.0 & -3.7262 & 24.8619 & -0.15 & 0.88 \\
\hline \multicolumn{7}{|l|}{ Gender } \\
\hline Male & $364(99.2)$ & 56.5 & -9.2321 & 76.6343 & -0.12 & 0.90 \\
\hline Female & $3(0.8)$ & 66.0 & Referent & & & \\
\hline \multicolumn{7}{|l|}{ Medical disorders } \\
\hline Congestive heart failure & $29(7.9)$ & 114.0 & 58.0000 & 24.5427 & 2.36 & 0.02 \\
\hline Coronary artery disease & $83(22.6)$ & 88.0 & 36.0000 & 15.7661 & 2.28 & 0.02 \\
\hline Hypertension & $244(66.5)$ & 64.5 & 23.0620 & 14.6306 & 1.58 & 0.12 \\
\hline Diabetes & $99(27.0)$ & 88.0 & 36.0000 & 14.2310 & 2.53 & 0.01 \\
\hline Chronic obstructive pulmonary disease & 47 (12.8) & 70.0 & 18.0000 & 21.2238 & 0.85 & 0.40 \\
\hline Any medical condition & $281(76.6)$ & 193.0 & 28.0000 & 16.2706 & 1.72 & 0.09 \\
\hline \multicolumn{7}{|l|}{ Psychiatric disorders } \\
\hline Depression & $47(12.8)$ & 108.0 & 55.1083 & 20.0249 & 2.75 & 0.006 \\
\hline Anxiety & $17(4.6)$ & 118.0 & 62.0000 & 33.2869 & 1.86 & 0.06 \\
\hline Dementia & $10(2.7)$ & 21.5 & -24.8090 & 42.4349 & -0.58 & 0.56 \\
\hline Post-traumatic stress disorder & $18(4.9)$ & 115.0 & 67.0759 & 31.9511 & 2.10 & 0.04 \\
\hline Schizophrenia & $3(0.8)$ & 179.0 & 122.2794 & 75.5686 & 1.62 & 0.11 \\
\hline Bipolar disorder & $5(1.4)$ & 53.0 & -4.0000 & 59.5244 & -0.07 & 0.95 \\
\hline Alcohol & $66(18.0)$ & 53.5 & -2.5543 & 17.9672 & -0.14 & 0.89 \\
\hline Any mental disorder & $120(32.9)$ & 226.0 & 15.5027 & 14.8695 & 1.04 & 0.30 \\
\hline
\end{tabular}

Data shown are for 367 patients diagnosed as having colorectal cancer in one tertiary centre from June 2001 to June 2007. 
Table 2 Waiting times between referral to and performance of colonoscopy presented for several diagnostic clues

\begin{tabular}{|c|c|c|c|c|}
\hline \multirow[b]{2}{*}{ Clues $(n=634)$} & \multirow{2}{*}{$\begin{array}{l}\text { All patients } \\
(\mathrm{n}=367) \\
\text { Median wait } \\
\text { in days }\end{array}$} & $\begin{array}{l}\text { Wait }>60 \\
\text { days }(n=178) \\
\end{array}$ & $\begin{array}{l}\text { Wait }<60 \\
\text { days }(n=189)\end{array}$ & \multirow[b]{2}{*}{ p Value } \\
\hline & & \multicolumn{2}{|c|}{ n (\%) } & \\
\hline $\begin{array}{l}\text { Iron deficiency anaemia } \\
(\mathrm{n}=47)\end{array}$ & 14.0 & $14(4.6)$ & $33(9.9)$ & 0.01 \\
\hline $\begin{array}{l}\text { Faecal occult blood test } \\
\text { positive }(n=150)\end{array}$ & 92.0 & $95(31.5)$ & $55(16.6)$ & $<0.0001$ \\
\hline $\begin{array}{l}\text { Abnormal CT scan } \\
(n=20)\end{array}$ & 4.0 & $2(0.7)$ & $18(5.4)$ & 0.0006 \\
\hline $\begin{array}{l}\text { Suspected mass } \\
(\mathrm{n}=11)\end{array}$ & 10.0 & $1(0.3)$ & $10(3.0)$ & 0.01 \\
\hline $\begin{array}{l}\text { Haematochesia } \\
(n=100)\end{array}$ & 75.0 & $58(19.2)$ & $42(12.7)$ & 0.02 \\
\hline $\begin{array}{l}\text { Constipation } \\
(n=14)\end{array}$ & 36.5 & $5(1.7)$ & $9(2.7)$ & 0.37 \\
\hline $\begin{array}{l}\text { Abdominal pain } \\
(n=14)\end{array}$ & 4.0 & $1(0.3)$ & $13(3.9)$ & 0.002 \\
\hline $\begin{array}{l}\text { Weight loss } \\
(n=15)\end{array}$ & 31.0 & $4(1.3)$ & $11(3.3)$ & 0.10 \\
\hline Melena ( $n=12$ ) & 26.0 & $4(1.3)$ & $8(2.4)$ & 0.32 \\
\hline $\begin{array}{l}\text { History of polyps } \\
(n=26)\end{array}$ & 221.0 & $21(7.0)$ & $5(1.5)$ & 0.0006 \\
\hline $\begin{array}{l}\text { Obstruction } \\
(\mathrm{n}=22)\end{array}$ & 0.0 & $1(0.3)$ & $21(6.3)$ & $<0.0001$ \\
\hline $\begin{array}{l}\text { Other lower Gl symptoms } \\
(\mathrm{n}=24)\end{array}$ & 47.0 & $10(3.3)$ & $14(4.2)$ & 0.55 \\
\hline $\begin{array}{l}\text { Flex sigmoidoscopy } \\
\text { positive }(n=12)\end{array}$ & 43.5 & $5(1.7)$ & $7(2.1)$ & 0.68 \\
\hline $\begin{array}{l}\text { Barium enema positive } \\
(n=24)\end{array}$ & 16.5 & $6(2.0)$ & $18(5.4)$ & 0.02 \\
\hline $\begin{array}{l}\text { Colon cancer screening } \\
(n=23)\end{array}$ & 203.0 & $18(6.0)$ & $5(1.5)$ & 0.003 \\
\hline Anaemia $(n=59)$ & 69.0 & $32(10.6)$ & $27(8.1)$ & 0.29 \\
\hline $\begin{array}{l}\text { Ileocolitis/fissure/Crohn } \\
\text { disease }(n=3)\end{array}$ & 2.0 & $0(0.0)$ & $3(0.9)$ & 0.25 \\
\hline $\begin{array}{l}\text { Surgical indications } \\
\text { (ano-rectal stricture, } \\
\text { diverticulitis/abscess, } \\
\text { etc.) }(n=33)\end{array}$ & 114.0 & $19(6.3)$ & $14(4.2)$ & 0.24 \\
\hline
\end{tabular}
centre from June 2001 to June 2007.

significantly associated with wait times of $<60$ days. Conversely, other clues such as positive FOBT, haematochesia and history of polyps were associated with $>60$-day wait times. Longer wait times were also more likely for referrals that requested colonoscopy for 'screening' despite the presence of other diagnostic clues.

The use of CPOE-generated referrals has potential for overcoming several types of communication failures between the PCP and specialist. Breakdowns in referral communication due to inadequate or absent information transmission have been previously described in healthcare systems without CPOEgenerated referral requests. ${ }^{10}{ }^{18-20}$ In one study from Brigham and Women's Hospital in Boston prior to the use of computerised referral requests, almost $68 \%$ of specialists reported not receiving any information from the PCP prior to the referral visit. ${ }^{18}$ Other studies have described communication breakdowns where the consultant and the PCP do not agree for the reason for referral. ${ }^{21}$ An added benefit of using CPOE is provision of templates or checkboxes to the referring physician when requesting a colonoscopy. This information can potentially be used to generate a likelihood score for CRC from an evidencebased algorithm, which can rationally inform colonoscopy scheduling.
We found that several diagnostic clues were associated with shorter wait times to diagnostic colonoscopy, suggesting the presence of some prioritisation mechanism to schedule procedures. However, seemingly logical prioritisation strategies may not be supported by current evidence. For example, a recent meta-analysis concluded that most 'alarm' features such as anaemia, change in bowel habits and weight loss have poor sensitivity and specificity for the diagnosis of CRC. ${ }^{22}$ Shorter wait times for referrals documenting obstruction and abdominal pain occurred because the majority $(74.3 \%)$ of these were emergent inpatient referrals. Additionally, clues suggesting the presence of a tumour, such as abnormal imaging or mass, were associated with short wait times. Contrary to what we expected, clues that signified bleeding, such as positive FOBT and haematochesia, were associated with a wait time longer than 60 days.

Consistent with previous literature, we found patient nonadherence to play a significant role in timeliness of diagnostic colonoscopy procedures. ${ }^{3} 2324$ Our findings underscore the need for future efforts to improve adherence to diagnostic colonoscopies. This is especially important in systems with constrained endoscopic capacity, where there may be lengthy delays before procedures can be rescheduled. Most of the work on improving patient adherence is mostly focused on screening colonoscopy 2526 and could potentially be applied to diagnostic procedures, where the yield of the procedure is expected to be higher.

Our findings suggest that timeliness may relate to "how you ask' through CPOE. ${ }^{27}$ For instance, we observed longer wait

Table 3 Association between referral request characteristics and time to colonoscopy using univariate quantile regression for all patients $(n=367)$ diagnosed as having colorectal cancer in one tertiary care centre from June 2001 to June 2007

\begin{tabular}{|c|c|c|c|c|c|}
\hline \multirow[b]{2}{*}{ Independent variable } & \multirow[b]{2}{*}{ n (\%) } & \multicolumn{4}{|c|}{ Median time } \\
\hline & & Days & Coefficient & SE & p Value \\
\hline \multicolumn{6}{|l|}{ Model 1} \\
\hline \multicolumn{6}{|c|}{ Provisional diagnosis (clue codes) } \\
\hline 1clue & $166(45.2)$ & 54.5 & Referent & & \\
\hline 2 clues & $145(39.5)$ & 83.0 & 28.8448 & 12.1326 & 0.02 \\
\hline 3 clues & $46(12.5)$ & 36.5 & -15.2789 & 17.7847 & 0.39 \\
\hline $4+$ clues & $10(2.7)$ & 4.0 & -50.1552 & 34.7546 & 0.15 \\
\hline \multicolumn{6}{|l|}{ Model 2} \\
\hline \multicolumn{6}{|l|}{ Inpatient } \\
\hline Yes & $84(22.9)$ & 2.0 & Referent & & $<0.0001$ \\
\hline No & $283(77.1)$ & 84.0 & 82.0000 & 5.4216 & \\
\hline \multicolumn{6}{|l|}{ Model 3} \\
\hline \multicolumn{6}{|l|}{ Urgency marked } \\
\hline Routine & $184(50.1)$ & 107.5 & Referent & & \\
\hline Next available & $16(4.4)$ & 84.0 & -18.8797 & 9.7942 & 0.05 \\
\hline$<30$ days & $44(12.0)$ & 69.0 & -37.7064 & 6.3060 & $<0.0001$ \\
\hline$<1$ week & $123(33.5)$ & 3.0 & -104.471 & 4.3765 & $<0.0001$ \\
\hline \multicolumn{6}{|l|}{ Model 4} \\
\hline \multicolumn{6}{|l|}{ Specialty of provider } \\
\hline Primary care & $277(75.5)$ & 70.0 & Referent & & \\
\hline Non-primary care & $90(24.5)$ & 14.0 & -56.0000 & 13.3429 & $<0.0001$ \\
\hline \multicolumn{6}{|l|}{ Model 5} \\
\hline \multicolumn{6}{|l|}{ Non-electronic contact } \\
\hline Inpatient contact & $84(22.9)$ & 2.0 & -97.0000 & 5.3366 & $<0.0001$ \\
\hline Outpatient contact & $42(11.4)$ & 20.0 & -75.8811 & 7.0426 & $<0.0001$ \\
\hline No contact & $241(65.7)$ & 99.0 & Referent & & \\
\hline \multicolumn{6}{|l|}{ Model 6} \\
\hline \multicolumn{6}{|c|}{ Patient adherent to 1 st referral } \\
\hline Yes & $313(85.3)$ & 41.0 & Referent & & $<0.0001$ \\
\hline No & $53(14.4)$ & 308.0 & 267.0000 & 15.5598 & \\
\hline
\end{tabular}


Table 4 Potential predictors of wait times between referral and performance of colonoscopy in 367 patients diagnosed as having colorectal cancer during June 2001 to June 2007: results of multivariable quantile regression

\begin{tabular}{|c|c|c|c|c|c|}
\hline Independent variable & $\mathbf{N}(\%)$ & Median time & Coefficient & SE & p Value \\
\hline \multicolumn{6}{|l|}{ No of clues } \\
\hline 1 clue & $166(45.2)$ & 54.5 & Referent & & \\
\hline 2 clues & $145(39.5)$ & 83.0 & 1.0000 & 3.3057 & 0.76 \\
\hline 3 clues & $46(12.5)$ & 36.5 & -21.0000 & 4.8109 & $<0.0001$ \\
\hline $4+$ clues & $10(2.7)$ & 4.0 & 0.0000 & 9.4250 & 1.00 \\
\hline \multicolumn{6}{|l|}{ Inpatient } \\
\hline Yes & $84(22.9)$ & 2.0 & Referent & & \\
\hline No & $283(77.1)$ & 84.0 & 55.6704 & 6.5823 & $<0.0001$ \\
\hline \multicolumn{6}{|l|}{ Urgency marked } \\
\hline Routine & $184(50.1)$ & 107.5 & Referent & & \\
\hline Next available & $16(4.4)$ & 84.0 & -32.4893 & 7.4358 & $<0.0001$ \\
\hline$<30$ days & $44(12.0)$ & 69.0 & -37.0555 & 4.8338 & $<0.0001$ \\
\hline$<1$ week & $123(33.5)$ & 3.0 & -21.0000 & 5.5868 & 0.0002 \\
\hline \multicolumn{6}{|l|}{ Specialty of provider } \\
\hline Primary care & $277(75.5)$ & 70.0 & Referent & & \\
\hline Non-primary care & $90(24.5)$ & 14.0 & -1.0000 & 3.8892 & 0.80 \\
\hline \multicolumn{6}{|l|}{ Non-electronic (verbal) contact } \\
\hline $\begin{array}{l}\text { Inpatient referrals (always require } \\
\text { additional verbal contact) }\end{array}$ & $84(22.9)$ & 2.0 & -760.000 & 17.7711 & $<0.0001$ \\
\hline Outpatient verbal contact & $42(11.4)$ & 20.0 & -60.0000 & 5.8490 & $<0.0001$ \\
\hline No contact & $241(65.7)$ & 99.0 & Referent & & \\
\hline \multicolumn{6}{|l|}{ Patient adherent to first referral } \\
\hline Yes & $313(85.3)$ & 41.0 & Referent & & \\
\hline No & $53(14.4)$ & 308.0 & 231.0000 & 4.3617 & $<0.0001$ \\
\hline
\end{tabular}

times when providers inappropriately listed 'screening' as the reason for the diagnostic colonoscopy despite the presence of other diagnostic clues in the patient's record. Similarly, using an unqualified diagnosis of 'anaemia' was associated with a longer lag time than when 'iron-deficiency anaemia' was used. Consultants may find it cumbersome to perform additional chart reviews to look for clues other than those provided in the referral request. Thus, effective electronic communication using CPOE requires providers to receive proper training on how best to use referral templates. Obligatory fields in referral templates may also help but do not guarantee the accuracy of information. Work on use and acceptability of templates for gastroenterology referrals at this institution is ongoing. Future research, preferably using prospective studies, is also needed to confirm our findings in other healthcare systems that use CPOE.

According to a recent Cochrane review, interventions to improve outpatient referrals from primary care to secondary care are needed, and only a limited number of rigorous evaluations exist to inform policy. ${ }^{28}$ To our knowledge, this is the first study that evaluates how characteristics of CPOE-generated referral content affect the timeliness of referral completion. Our study involved several satellite clinics, a large study sample and a large number of referring providers. Providers in the VA are trained and well versed with CPOE, which has been used in most VA facilities since before 2002.

Our study had several limitations. The study population included only patients who were eventually diagnosed as having CRC. Therefore, the findings may not apply to the vast majority of requests for colonoscopy in which CRC is not found, and any selection bias resulting from our methods is difficult to detect. Additionally, the study population (predominantly male veterans) and the VA setting may make our findings less generalisable to other practices, especially those that do not use electronic referrals. We also did not collect data on clinical outcomes related to delays in CRC diagnosis. Previous studies of the association between diagnostic delays and CRC outcomes have yielded conflicting results. ${ }^{29-31}$ Although the precise definition of a meaningful delay is unclear, delays in care are relevant facets of patient safety and satisfaction.

In conclusion, we found that several referral characteristics were associated with lag times for diagnostic colonoscopy in CRC patients, including the type as well as the frequency of diagnostic clues provided to the consultants (more than one clue is better than one or no clues), flagging of urgency and documenting verbal discussions with consultants to expedite referrals. In systems with limited endoscopic capacity, attention to these aspects of diagnostic information transmitted through CPOE based referrals may help reduce delays in CRC diagnosis.

Funding The study was supported by an NIH K23 career development award (K23CA125585) to HS, the VA National Center of Patient Safety, and in part the Houston VA HSRgD Center of Excellence (HFP90-020).

\section{Competing interests None.}

Ethics approval Ethics approval was provided by the Baylor College of Medicine.

Provenance and peer review Not commissioned; externally peer reviewed.

\section{REFERENCES}

1. Gandhi TK, Kachalia A, Thomas EJ, et al. Missed and delayed diagnoses in the ambulatory setting: a study of closed malpractice claims. Ann Intern Med 2006;145:488-96.

2. Phillips RL Jr, Bartholomew LA, Dovey SM, et al. Learning from malpractice claims about negligent, adverse events in primary care in the United States. Qual Saf Health Care 2004;13:121-6.

3. Fisher DA, Jeffreys A, Coffman CJ, et al. Barriers to full colon evaluation for a positive fecal occult blood test. Cancer Epidemiol Biomarkers Prev 2006;15:1232-5

4. Yabroff $\mathbf{K}$, Washington KS, Leader A, et al. Is the promise of cancer-screening programs being compromised? Quality of follow-up care after abnormal screening results. Med Care Res Rev 2003;60:294-331.

5. Freeman HP, Muth BJ, Kerner JF. Expanding access to cancer screening and clinical follow-up among the medically underserved. Cancer Pract 1995:3:19-30

6. Young CJ, Sweeney JL, Hunter A. Implications of delayed diagnosis in colorectal cancer. Aust N Z J Surg 2000;70:635-8. 
7. Singh H, Sethi S, Raber M, et al. Errors in cancer diagnosis: current understanding and future directions. J Clin Oncol 2007;25:5009-18.

8. Singh H, Daci K, Petersen LA, et al. Missed opportunities to initiate endoscopic evaluation for colorectal cancer diagnosis. Am J Gastroenterol 2009;104:2543-54.

9. Wattacheril J, Kramer JR, Richardson $\mathrm{P}$, et al. Lagtimes in diagnosis and treatment colorectal cancer: determinants and association with cancer stage and survival. Aliment Pharmacol Ther 2008;28:1166-74.

10. Jiwa M, Mathers N, Walters S. Quality of information on referrals to colorectal surgeons: towards consensus. Curr Med Res Opin 2002;18:72-7.

11. Jumah KB, Gordon-Harris L, Agahowa Jl. Common faults in filling of radiological request forms. East Afr Med J 1995;72:744-5.

12. Jenkins RM. Quality of general practitioner referrals to outpatient departments: assessment by specialists and a general practitioner. Br J Gen Pract 1993:43:111-13.

13. Singh H, Kadiyala H, Bhagwath $\mathrm{G}$, et al. Using a multifaceted approach to improve the follow-up of positive fecal occult blood test results. Am J Gastroenterol 2009;104:942-52.

14. El-Serag HB, Petersen L, Hampel H, et al. The use of screening colonoscopy for patients cared for by the Department of Veterans Affairs. Arch Intern Med 2006;166:2202-8

15. VHA Directive 2007-004: Colorectal Cancer Screening. Department of Veterans Affairs and Veterans Health Administration. 1-12-2007. Ref Type: Report. http://www1.va.gov/VHAPUBLICATIONS/ViewPublication.asp?pub ID =1530.

16. Koenker R. Quantile regression. Cambridge: Cambridge University Press, 2005

17. Hao L, Naiman DQ. Quantile regression. Thousand Oaks, CA: Sage Publications, 2007.

18. Gandhi TK, Sittig DF, Franklin M, et al. Communication breakdown in the outpatient referral process. J Gen Intern Med 2000;15:626-31.

19. Stille CJ, McLaughlin TJ, Primack WA, et al. Determinants and impact of generalist-specialist communication about pediatric outpatient referrals. Pediatrics 2006;118:1341-9.
20. Stille CJ, Primack WA, Savageau JA. Generalist-subspecialist communication for children with chronic conditions: a regional physician survey. Pediatrics 2003;112:1314-20.

21. Lee T, Pappius EM, Goldman L. Impact of inter-physician communication on the effectiveness of medical consultations. Am J Med 1983;74:106-12.

22. Ford AC, Veldhuyzen van Zanten SJO, Rodgers CC, et al. Diagnostic utility of alarm features for colorectal cancer: systematic review and meta-analysis. Gut 2008; 57:1545-53.

23. Zheng YF, Saito T, Takahashi M et al. Factors associated with intentions to adhere to colorectal cancer screening follow-up exams. BMC Public Health 2006;6:272

24. Denberg TD, Melhado TV, Coombes JM, et al. Predictors of nonadherence to screening colonoscopy. J Gen Intern Med 2005;20:989-95.

25. Coombes JM, Steiner JF, Bekelman DB, et al. Clinical outcomes associated with attempts to educate patients about lower endoscopy: a narrative review. J Community Health 2008:33:149-57.

26. Denberg TD, Coombes JM, Byers TE, et al. Effect of a mailed brochure on appointment-keeping for screening colonoscopy: a randomized trial. Ann Intern Med 2006;145:895-900.

27. Goldman L, Lee T, Rudd P. Ten commandments for effective consultations. Arch Intern Med 1983:143:1753-5.

28. Akbari A, Mayhew A, Al-Alawi MA, et al. Interventions to improve outpatient referrals from primary care to secondary care. Cochrane Database Syst Rev 2008;(4):CD005471.

29. Gonzalez-Hermoso F, Perez-Palma J, Marchena-Gomez J, et al. Can early diagnosis of symptomatic colorectal cancer improve the prognosis? World J Surg 2004:28:716-20

30. Korsgaard M, Pedersen L, Sorensen HT, et al. Delay of treatment is associated with advanced stage of rectal cancer but not of colon cancer. Cancer Detect Prev 2006:30:341-6.

31. Ramos M, Esteva M, Cabeza E, et al. Relationship of diagnostic and therapeutic delay with survival in colorectal cancer: a review. Eur J Cancer 2007:43:2467-78. 